\title{
Palatal perforation in Erythema Nodosum Leprosum (ENL) case of hansen's disease: A case report
}

\author{
Vivekanand C. Giri ${ }^{1, *}$, Sunita Bharati ${ }^{2}$, Pugazhenthan Thangaraju ${ }^{3}$, M. K. Showkath Ali $^{4}$ \\ ${ }^{\mathbf{1}}$ Deputy Director, ${ }^{\mathbf{2}}$ Assistant Professor, ${ }^{3}$ Medical Officer, ${ }^{\mathbf{4}}$ Director, ${ }^{\mathbf{1 , 3 4}}$ Central Leprosy Teaching and Research Institute, \\ Chengalpattu, Tamil Nadu, ${ }^{2}$ Shri Sathya Sai Medical College \& Research Institute, Ammapettai, Tamil Nadu, India
}

\section{*Corresponding Author:}

Email: drvivekgiri@gmail.com

\begin{abstract}
Leprosy (Hansen's disease) is mainly affecting skin \& nerve. Lepra reaction is common amongst leprosy patient. We report 64 year female patient who completed MB-MDT treatment and was on steroid therapy for treatment of ENL reaction. We observed unusual presentation of palatal perforation which rarely seen in ENL case. On examination it found that perforation was present on hard palate midline at the level of first molar tooth. Such type of presentation rarely seen in ENL cases till date few such reports have published in the journals.
\end{abstract}

Keyword: Multi-bacillary leprosy case, Chronic ENL reaction, palatal perforation.

\section{Introduction}

Leprosy (Hansen's disease) is chronic Inflammatory disease mainly affects the skin and nerves. In India around 125750 new leprosy cases detected annually accounting about 58.8\% of global disease burden (WER-WHO 2015). Lepra reaction can occur before or during treatment or completion treatment. Lepra Reaction more common in Multibacillary leprosy case. Erythema Nodosum Leprosum (ENL) classically presents as tender evanescent skin nodules involving extremities, trunk, and face but may appear at any site leading to nerve damage and organ involvement. Mucosal involvement in ENL is uncommon, (Kothawala 2015) The type 2 lepra reaction / erythema nodosum leprosum (ENL) classically involves extremities and face. Besides to the classical lesions of type 2 lepra reaction sometimes rare findings of vesicular lesions with necroticans may be observed (Swain JP 2008)

\section{Case Report}

A female patient age 64 years known case of MB Hansen's disease, who has completed MB-MDT (Adult) 2 year back and taking medical intervention for chronic ENL from CLTRI Hospital, a tertiary care hospital exclusively for leprosy services. Patient had few spell of ENL for which she has taken steroid and other medication. Case was reported to hospital with complain of nodular swelling all over body, fever and difficulty in swallowing food. On examination it was noticed that patient was known case of chronic ENL and frequently on medication. Patient was on steroid regimen (prednisolone) for the treatment of chronic ENL. On local examination it has observed that perforation of hard palate seen in middle. The size was $1 \times 1 \times 1.5 \mathrm{~cm}$ in dimension. The perforation was mainly seen midline at level of first molar tooth. The margin of perforation observed with some necrotic tissue.

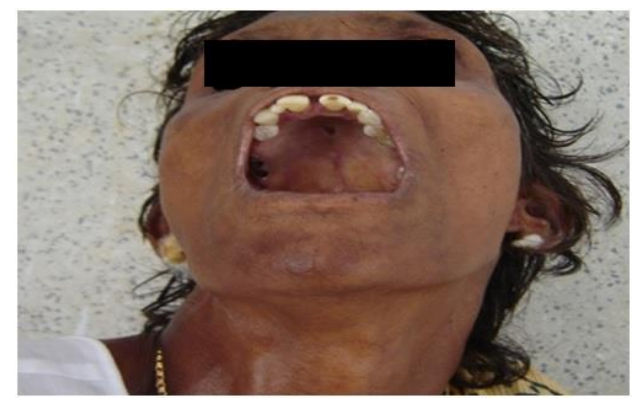

Fig. 1

\section{Discussion}

The term 'palate' refers to roof of mouth. The palate consists of two parts: 1- hard palate, which forms anterior four-fifth of the palate 2-soft palate, which forms posterior one-fifth of palate. Hard palate is a partition between nasal and oral cavities. It's anterior two-third is formed by palatine processes of maxillae and posterior one-third by horizontal plates of palatine bones.

The Management of lepra reaction is biggest challenge to reduce amount of disability. Chronic ENL reaction case shows various systemic manifestation. The ENL reaction is more common in lepromatus leprosy. Mucosal involvement in ENL is uncommon, and its occurrence over glans is extremely rare observed by (Kothiwala SK 2015). The ENL reaction is more common in adult however Pandhi et al 2005 reported a necrotic erythema nodosum leprosum in a 9-year-old boy with no pre-existing evidence of leprosy. The lesions resolved completely following multi-bacilliary multi-drug therapy for 12 months, non-steroidal antiinflammatory drugs and corticosteroids. Systematic review of evidence on ENL incidence $(1.2 \%)$ of all leprosy cases $(13.7 \%)$ of MB cases develop ENL. Regional differences could not be confirmed. Multiple 
ENL episodes occurred in 39 to $77 \%$ of ENL patients, with an average of 2.6. Some studies find a peak in ENL incidence in the first year of treatment (Voorend CGN 2013). In this present case patient older age might have played some role in formation of necrotic perforation.

Funding: No funding sources.

Conflict of interest: None declared.

\section{References}

1. Weekly Epidemiological Record, WHO. Global Leprosy Update: Need for early case detection. 2015;90:461-76.

2. H K Kar. Lepra Reaction. IAL text Book of leprosy, JP Publication, $2^{\text {nd }}$ Edition, 2015

3. Kothiwala SK, Khandpur S, Singh MK, Durgapal. Erythema nodosum leprosum on glans penis: unusual manifestation of common disease P. Int $J$
Dermatol 2015;54(9):1060-3. doi: 10.1111/ijd.12772. Epub 2014 Dec 29.

4. Swain JP, Soud A, Agarwal SK. Necrotic erythema nodosum leprosum with oral mucosal involvement. Indian J Lepr 2008;80(2):175-8

5. Pandhi D, Mehta S, Agrawal S, Singal A Erythema nodosum leprosum necroticans in a child-an unusual manifestation. Int J Lepr Other Mycobact Dis 2005;73(2):122-26.

6. Voorend CGN, Post EB (2013) A Systematic Review on the Epidemiological Data of Erythema Nodosum Leprosum, a Type 2 Leprosy Reaction. PLoS Negl Trop Dis 7(10):e2440.

7. Vishram Singh. Text Book of Anatomy: Head, Neck and Brain, $2^{\text {nd }}$ Edition, Elsevier India 2014,III: 231.

How to cite the article: Giri V., Bharati S., Thangaraju P., Ali S. Palatal perforation in Erythema Nodosum Leprosum (ENL) case of hansen's disease: A case report. Indian J Anat Surg Head Neck Brain 2018;4(3):89-90. 